\title{
AN UNUSUAL CASE OF VESICAL CALCULUS WITH IUCD AS NIDUS
}

Raghuveer $^{1}$, Deepak Bolbandi², Prathvi Shetty ${ }^{3}$, L. N. Raju ${ }^{4}$, Sridhar Reddy. ${ }^{5}$

\section{HOW TO CITE THIS ARTICLE:}

Raghuveer, Deepak Bolbandi, Prathvi Shetty, L. N. Raju, Sridhar Reddy. "An unusual case of Vesical Calculus with IUCD as Nidus". Journal of Evolution of Medical and Dental Sciences 2014; Vol. 3, Issue 40, September 01; Page: 10224-10228, DOI: $10.14260 /$ jemds/2014/3329

ABSTRACT: Foreign bodies in the bladder and ensuing calculus formation around it is an unusual cause for intravesical stone formation. Iatrogenic cause due to intrauterine device (popular and safe method of contraception due to its high efficacy, low risk and low-cost) migration to adjacent organs is a rare one with only a few reports in the medical literature. Treatment of foreign bodies is determined by their size, location, shape, and mobility. In most cases, minimally invasive procedures such as endoscopic removal are recommended. We report a case of a 39 year old female who presented with chronic urinary symptoms USG, X-ray and CT scan showed the presence of IUCD with calculus. Cystoscopic examination confirmed the diagnosis and allowed removal of the intrauterine contraceptive device and calculus.

KEYWORDS: Foreign bodies in bladder migrated IUCD.

INTRODUCTION: From times unknown foreign bodies in the urinary bladder has always been an interesting topic. Different variety of foreign bodies like surgical gauze, teflon beak of TUR sheath, intrauterine contraceptive device (IUCD), metal wire, carrot, lead pencil, hernia mesh, ball pen and thermometer have been extracted from urinary bladder. ${ }^{1}$ Foreign bodies reach urinary bladder either through iatrogenic means during bladder surgery or surgery on adjacent organs or self-introduction. Migration of materials from other adjacent organs like uterus, vagina is another rare cause. Only around 50+ cases of migrated IUCDs leading to vesical calculus have been reported till date.

CASE REPORT: A 39 years old female, presented to urology OPD with complaints of intermittent lower abdominal pain accompanied with episodes of dysuria since twelve years. She was treated for UTI on these occasions and symptoms relieved on taking medications. She had undergone intrauterine contraceptive device (IUCD) insertion 19 years back in a private clinic, after having two children.

However she conceived again one year later following IUCD insertion. The patient ignored about IUCD and failed to reveal about the same to her treating doctor. Following delivery she underwent tubectomy.

On clinical examination, vitals were stable. Per abdomen examination, suprapubic tenderness was present. Systemic examination was within normal limits. Per vaginal examination revealed only mild tenderness in the anterior vaginal wall. On ultrasound KUB (kidney, ureter and bladder), there was a hyperechoic immobile lesion in the posterior wall of bladder with post acoustic shadowing suggestive of calculus. Also the lesion showed internal echoing and measured $3 \times 4 \mathrm{~cm}$. (Fig 1).

Radiologists insisted on CT KUB for determining the unusual internal echoes and immobility. On plain CT KUB, the T-tube with long limb end having calculus formed was clearly delineated. It was also noted that the short limb of T-tube was seen poking out of the bladder wall unrelated to any other surrounding structure (Fig 3). Urine microscopy showed pus cells and RBCs. Urine culture showed Klebsiella sensitive to Amikacin and same was initiated. 
With rest of the laboratory parameters within normal limits patient was taken for surgery under spinal anesthesia. On cystoscopy, the calculus was visible and same was broken with lithotripter using $20 \mathrm{f}$ amplatz sheath and 18f nephroscope (Fig 4). Now the IUCD was clearly visible with only the longer limb of $\mathrm{T}$ in the bladder around which the calculus had formed.

The horizontal limb of the t-tube had buried into the bladder wall. With the long end held with grasper the T-tube was pulled out in to (Fig 5). However there was no bleeding or perforation of the bladder wall. A 20f per urethral Foley's catheter was inserted. Post operatively patient recovered well and was discharged after 3 days after catheter removal. Patient was followed for 4 months.

DISCUSSION: Two types of stones are usually identified in the bladder; primary caused due to dietary and socioeconomic factors and secondary as a result of denovo (bladder outlet obstruction, neurogenic bladder, retained foreign bodies) or from maturation of stone nidi migrated from upper tract. A foreign body in bladder initially encrust with calcium oxalate, infection, struvite deposition on nascent stone.

Vast majority of foreign bodies are from iatrogenic interventions (slings, tvt, IUCD, vaginal pessaries, contraceptive diaphragms, eroded silk following radical prostatectomy, intra prostatic stents, eroded penile prosthesis, artificial urinary sphincters, and long term urinary drainage etc. selfmutilation plays minor role.

Intrauterine devices (IUD) have been used for more than 3 decades. More than 100 million women worldwide have been using IUD's. Uterine perforation is an uncommon complication of IUD. The incidence ranges from 0.2 to 9.6 per 1000 insertions. Due to the asymptomatic nature of the perforation, the true incidence of the uterus perforation by an IUD is most likely higher than reported.

The exact mechanism that causes uterine perforation and migration of the IUD is not entirely known. The most important factor related with this complication is probably the operator experience in IUD application. There are also many factors that affect uterine perforation, such as the uterine size, position, and timing of the insertion, congenital uterine anomalies and previous Cesarean section.

Patient may present with irritative voiding symptoms including frequency, dysuria, hematuria and stranguary. Some Patients occasionally present with no symptoms or complaint of minimal discomfort. Radio-opaque foreign bodies can easily be detected on KUB radiograph. X ray can be combined with ultrasonography and CT for confirmation.

The presence of intravesical foreign body is confirmed by cystoscopy and it will not only identify the type of location of foreign body but is the most adequate method for treatment. Most of the foreign bodies in the urinary bladder can be removed endoscopically using - Biopsy forceps, grasping forceps, stone punch, glass syringe, basket or cutting loop.

Recently, holmium laser was utilized successfully in division and removal of a synthetic urethral sling mesh in one patient and fragmentation of a tempered stainless steel surgical needle in another.

With the advent of minimally invasive techniques, most intravesical foreign bodies can be removed endoscopically. Open surgery is reserved for large foreign bodies or foreign bodies with large encrustations. As seen in our case, a high level of suspicion is required for diagnosis of unusual causes for intravesical calculus. 


\section{CASE REPORT}

Fig 1: Ultrasound KUB showed a hyperechoic immobile lesion in the posterior wall of bladder with post acoustic shadowing.

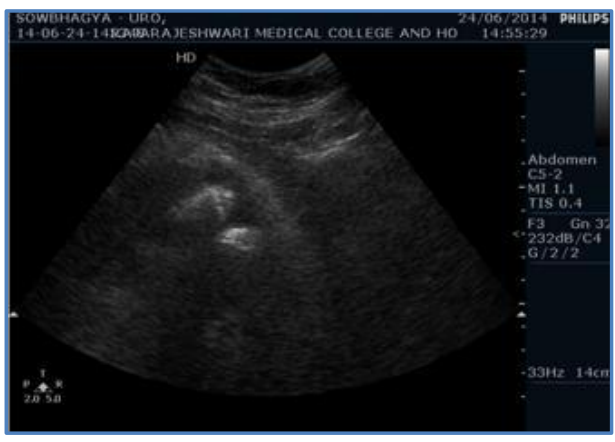

Fig. 1

Fig 2: X-ray KUB showing $\mathrm{Cu}-\mathrm{T}$ and calculus in the bladder.

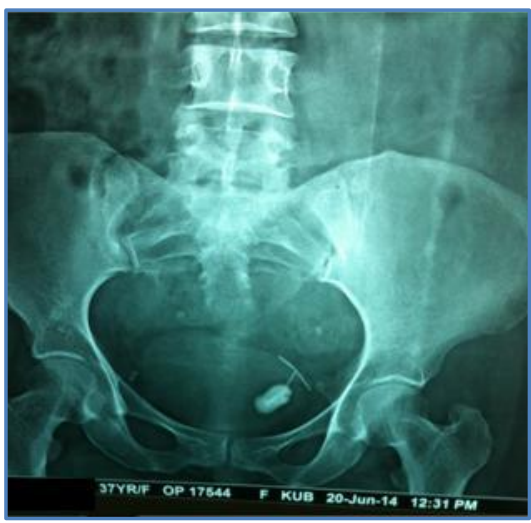

Fig. 2

Fig. 3: CT scan showing IUCD and calculus in at different levels.

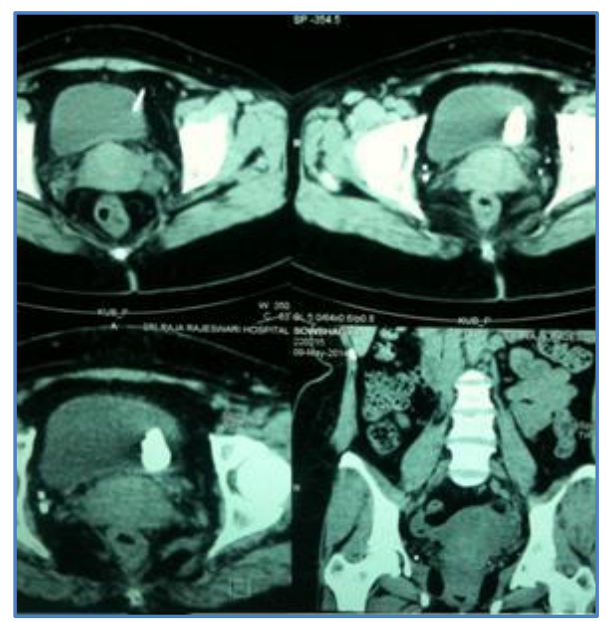

Fig. 3 


\section{CASE REPORT}

Fig 4: A. Cystoscopic view of the calculus. B. Visible IUCD soon after the stone was broken. C. IUCD held with grasper being removed.
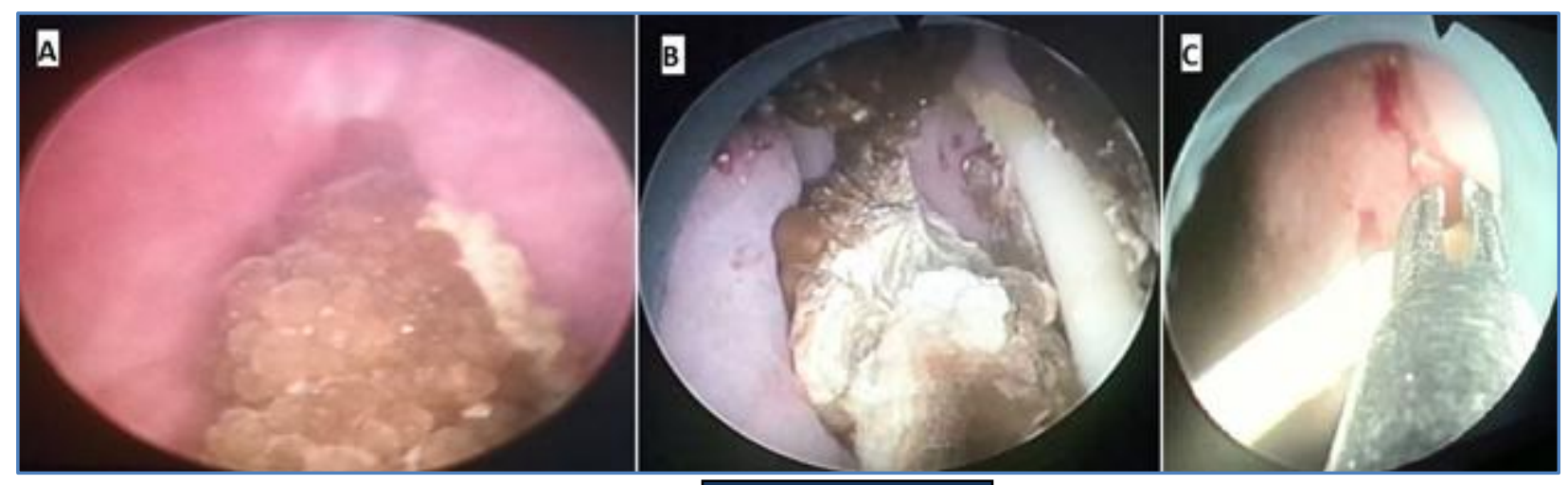

Fig. 4A, 4B, 4C

Fig 4: Migrated $\mathrm{Cu}$-T along with calculus.

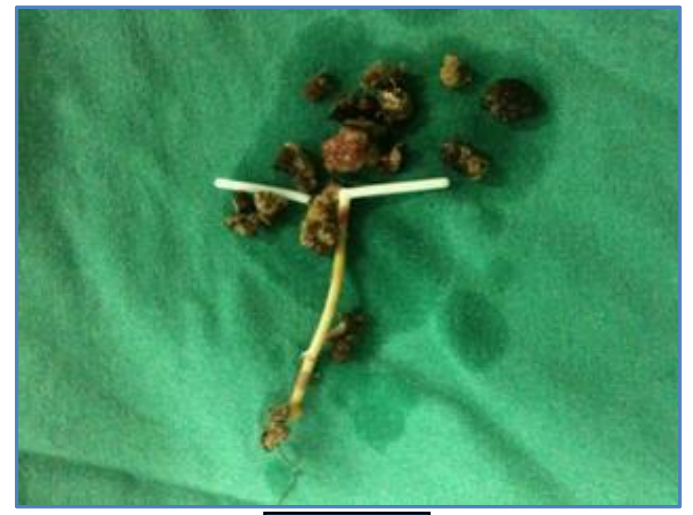

\section{Fig. 4}

\section{BIBLIOGRAPHY:}

1. Rafique M. Intravesical Foreign Bodies; Review and Current Management Strategies. Urol J. 2008 Fall; 5 (4): 223-31.

2. Tuncay YA, Tuncay E, Guzin K, Ozturk D, Omurcan C, Yucel N. Transuterine migration as a complication of intrauterine contraceptive devices: six case reports. Eur J Contracept Reprod Health Care 2004; 9: 194-200.

3. Guvel S, Tekin MI, Kilinc F, Peskircioglu L, Ozkardes H. Bladder stones around a migrated and missed intrauterine contraceptive device. Int J Urol 2001; 8 (2): 78-79.

4. Hiller N, Zagal I, Solomom I. Intravesical foreign bodies. The danger of eroticism. Urologia 1999; 66: 2.

5. Calı kan E, Oztürk N, Dilbaz BO, et al. Analysis of risk factors associated with uterine perforation by intrauterine devices. Eur J Contracept Reprod Health Care. 2003; 8: 150-5.

6. El-Hefnawy AS, El-Nahas AR, Osman Y, et al. Urinary complications of migrated intrauterine contraceptive device. Int Urogynecol J. 2008; 19: 241-5. 


\section{CASE REPORT}

\section{AUTHORS:}

1. Raghuveer

2. Deepak Bolbandi

3. Prathvi Shetty

4. L. N. Raju

5. Sridhar Reddy

\section{PARTICULARS OF CONTRIBUTORS:}

1. Post Graduate, Department of Urology, Rajarajeshwari Medical College and Hospital.

2. Assistant Professor, Department of Urology, Rajarajeshwari Medical College and Hospital.

3. Assistant Professor, Department of Urology, Rajarajeshwari Medical College and Hospital.

4. Associate Professor, Department of Urology, Rajarajeshwari Medical College and Hospital.
5. Professor, Department of Urology, Rajarajeshwari Medical College and Hospital.

\section{NAME ADDRESS EMAIL ID OF THE CORRESPONDING AUTHOR:}

Dr. Raghuveer Machiraju,

Rajarajeshwari Medical

College \& Hospital,

Kambipura, Mysore Road,

Bangalore-560074.

Email: 21raghuveer@gmail.com

Date of Submission: 17/08/2014.

Date of Peer Review: 18/08/2014.

Date of Acceptance: 25/08/2014.

Date of Publishing: 01/09/2014. 